\title{
Oral Acetazolamide after Boston Keratoprosthesis in Stevens Johnson Syndrome
}

\author{
Radhika Kumar, Claes H Dohlman and James Chodosh*
}

\begin{abstract}
Background: Stevens-Johnson syndrome/toxic epidermal necrolysis (SJS/TEN) is a rare but severe and sometimes fatal condition associated with exposure to medications; sulfamethoxazole is among the most common causes. We sought to address the safety of acetazolamide, a chemically related compound, in patients with prior SJS/TEN and glaucoma. A retrospective case series is described of patients at the Massachusetts Eye and Ear Infirmary who underwent keratoprosthesis surgery for corneal blindness from SJS/TEN, and later required oral acetazolamide for elevated intraocular pressure.

Findings: Over the last 10 years, 17 patients with SJS/TEN received a Boston keratoprosthesis. Of these, 11 developed elevated intraocular pressure that required administration of oral acetazolamide. One of 11 developed a mild allergic reaction, but no patient experienced a recurrence of SJS/TEN or any severe adverse reaction.

Conclusion: Although an increase in the rate of recurrent SJS/TEN due to oral acetazolamide would not necessarily be apparent after treating only 11 patients, in our series, acetazolamide administration was well tolerated without serious sequela.
\end{abstract}

Keywords: Stevens Johnson syndrome, Toxic epidermal necrolysis, Acetazolamide, Glaucoma

\section{Findings}

\section{Background}

Stevens Johnson syndrome and toxic epidermal necrolysis (SJS/TEN), two ends of a spectrum of severe adverse drug reactions affecting the skin and mucosa, typically result from hypersensitivity to a medication and manifest by acute sloughing of skin and mucous membranes. Secondary complications can be similar to burn patients with extensive loss of skin and mucosa, fever, hepatic, renal, and/or gastrointestinal involvement, sepsis, and death. Medications implicated in SJS/TEN include most commonly sulfonamides, anti-seizure medications, penicillins, and allopurinol, with onset of symptoms occurring within 1-8 weeks of drug administration [1-3]. SJS/ TEN has an incidence of 1 to 6 cases per million personyears, and carries an overall mortality up to $15 \%$ for SJS to $50 \%$ for TEN. Ocular involvement during the acute phase occurs in up to 50-69 \% of patients with SJS/TEN [4]. For survivors, severe dry eye, cicatricial ocular surface damage, and corneal blindness are feared outcomes.

* Correspondence: james_chodosh@meei.harvard.edu

Massachusetts Eye and Ear Infirmary, Harvard Medical School, Department of Ophthalmology, Boston, MA, USA
In one study, the prevalence of ocular complications of SIS was $20 \%$ at 3 months following onset of SJS/TEN [5]. In our experience, however, patients with chronic ocular complications of SJS/TEN tend to worsen with time.

In patients with loss of conjunctival fornices, keratinizing dry eye, and subsequent corneal blindness, the Boston keratoprosthesis type II, a collar button device of polymethylmethacrylate and titanium, is implanted to provide visual recovery [6]. However, postoperative glaucoma is common, even when a aqueous drainage device is implanted [7]. In Boston keratoprosthesis type II implantation, the eyelids are closed surgically around the prosthesis, as shown in Figure 1, after which, topical glaucoma drops have limited usefulness. Tube shunt failure after keratoprosthesis type II is common, and necessitates revision of the shunt or implantation of a second tube. Opening the fused eyelids for shunt revision or replacement, or for transcleral cyclophotocoagulation [7] may interfere with anatomic stability of the keratoprosthesis. Acetazolamide is a sulfonamide chemically distinct from sulfonamide antibiotics such as sulfamethoxazole. Use of oral acetazolamide or its sister drug methazolamide may be the only option in patients after Boston 


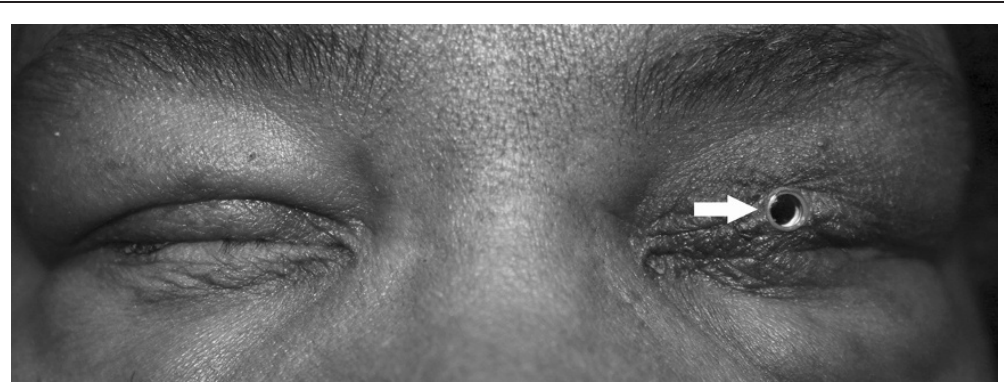

Figure 1 Clinical appearance of the Boston type II keratoprosthesis in the left eye of a patient with history of toxic epidermal necrolysis. Note the tight apposition between the eyelid skin and the keratoprosthesis stem (arrow).

keratoprosthesis type II or after osteo-odonto keratoprosthesis, a different technique for restoration of endstage cicatricial corneal blindness [8]. However, concerns over use of acetazolamide causing a second episode of SJS/TEN in keratoprosthesis patients have been raised [9], even when the drug initially associated with the patient's SJS/TEN is not of the same chemical class.

Herein, we review the current literature pertaining to the use of sulfa-derivative medications in patients with a history of SJS/TEN, and present a series of patients at the Massachusetts Eye and Ear Infirmary in whom acetazolamide was used to treat intraocular pressure rises after implantation of a Boston keratoprosthesis.

\section{Methods}

We performed a literature search using the search terms: Stevens-Johnson syndrome, toxic epidermal necrolysis, sulfa, Diamox, acetazolamide, allergy, and cross-reactivity. No articles were found that specifically addressed the safety of administration of sulfonamide nonantibiotics to patients with a history of SJS/TEN. With approval by the Human Studies Committee of the Massachusetts Eye and Ear Infirmary, we then performed a chart review of all patients with SJS/TEN who underwent Boston keratoprosthesis surgery from January 1, 2000 until December 31, 2010.

\section{Results}

We identified 17 such patients; eleven (Table 1) were found to have received oral acetazolamide to reduce intraocular pressure at some point following their keratoprosthesis surgery. One patient had a type I keratoprosthesis (without eyelid surgery) but all others had a type II keratoprosthesis (eyelids surgically fused closed).

Of the 11 patients who received oral acetazolamide, only one patient experienced an adverse reaction (warmth and pruritis); this occurred after 10 days of close monitoring. The affected patient never developed urticaria or dyspnea. Acetazolamide was stopped immediately upon development of symptoms, and no further adverse events occurred. It should be noted that the SJS/TEN in this patient was attributed to ibuprofen. The patient did not have a known allergy to acetazolamide, but had been told by her internist to avoid "sulfa" drugs due to their strong association with SIS/TEN. None of the patients in our series who were given acetazolamide reported sulfa as a cause of their SJS/TEN, but two reported the drug as an allergy. Interestingly, penicillin was thought to be the trigger for the SJS/TEN in both patients with sulfa allergy. Penicillin allergy seems to confer a heightened sensitivity to many other classes of medications [10]. Of the six patients who did not require oral acetazolamide, in three a sulfa drug caused their SJS/TEN, in two it occurred after treatment with penicillin, and in one patient the SJS/TEN was of unknown etiology (data not shown). All patients treated with oral acetazolamide demonstrated helpful reductions in intraocular pressure. In summary, acetazolamide was used in $11 \mathrm{SJS} / \mathrm{TEN}$ patients after keratoprosthesis, for a total of 16.3 person-years, with only one mild adverse reaction, and no reactivation of SJS/TEN.

\section{Discussion}

SJS/TEN manifests clinically as mucocutaneous erythma and blistering, and leads to variable degrees of full thickness necrosis of skin and mucosae. The best available evidence suggests that SJS/TEN is drug metabolite specific, cytotoxic T cell-driven, and perforin/granzyme B triggered [3,11-18]. Specific HLA types associate with an increased risk of SJS/TEN to particular drugs [19-21]. In addition, fas and fas ligand have been implicated in the disorder, and may contribute to the characteristic expansion of keratinocyte apoptosis as the condition progresses [1,3,22]. Given the very real risk of death and the significant morbidity associated with SIS/TEN, and the disorder's strong association with sulfonamides [2], controversy regarding the safety of acetazolamide in SJS/TEN is understandable. Furthermore, the rarity of SJS/TEN means that even a substantial increase in SJS/TEN incidence due to acetazolamide could be missed by individual physicians.

Although many different medications have been associated with SJS/TEN, the drug most commonly 
Table 1 Demographics of treated patients

\begin{tabular}{|c|c|c|c|c|c|c|c|}
\hline Pt. no. & $\begin{array}{c}\text { Age at } \\
\text { onset of SJS/TEN } \\
\text { (years) }\end{array}$ & $\begin{array}{l}\text { Inciting agent } \\
\text { for SJS/TEN }\end{array}$ & $\begin{array}{l}\text { Self-reported } \\
\text { drug allergies }\end{array}$ & $\begin{array}{c}\text { Time after surgery } \\
\text { when } \\
\text { acetazolamide } \\
\text { started (months) }\end{array}$ & $\begin{array}{c}\text { Presence of } \\
\text { glaucoma } \\
\text { drainage tube } \\
\text { pre-acetazolamide }\end{array}$ & $\begin{array}{c}\text { Time on } \\
\text { acetazolamide } \\
\text { (months) }\end{array}$ & $\begin{array}{c}\text { Adverse } \\
\text { reactions to } \\
\text { acetazolamide }\end{array}$ \\
\hline 1 & 43 & ibuprofen & NSAID & 1 day & Y & 10 days & $\begin{array}{l}\text { Warmth and } \\
\text { pruritis }\end{array}$ \\
\hline $2^{*}$ & 48 & sulindac & NSAID & 24 & $\mathrm{~N}$ & 1 & $\mathrm{~N}$ \\
\hline 3 & 40 & $\begin{array}{l}\text { allopurinol, } \\
\text { erythromycin, } \\
\text { colchicine }\end{array}$ & same & 9 & Y & 9 & $\mathrm{~N}$ \\
\hline 4 & 50 & Not known & terfenadine & 0 & $\mathrm{~N}$ & 31 & $\mathrm{~N}$ \\
\hline 5 & 3 & $\mathrm{PCN}$ & $\begin{array}{l}\text { PCN, sulfa, } \\
\text { erythromycin }\end{array}$ & 5 & $\mathrm{~N}$ & 1.5 & $\mathrm{~N}$ \\
\hline 6 & 36 & Not known & $\begin{array}{l}\text { PCN, cefazolin, } \\
\text { erythromycin }\end{array}$ & 2 & Y & 24 & $\mathrm{~N}$ \\
\hline 7 & 54 & $\begin{array}{l}\text { bupropion, } \\
\text { atenolol }\end{array}$ & same & 13 & Y & 30 & $\mathrm{~N}$ \\
\hline 8 & 25 & Not known & NKDA & 7 & Y & 24 & $\mathrm{~N}$ \\
\hline 9 & 13 & $\begin{array}{l}\text { aspirin, } \\
\text { ibuprofen }\end{array}$ & same & 0.75 & Y & 1.5 & $\mathrm{~N}$ \\
\hline 10 & Not known & Not known & PCN, codeine & Not known & Not known & 9 & $\mathrm{~N}$ \\
\hline 11 & 27 & $\mathrm{PCN}$ & PCN, sulfa & 2 & Y & 64 & $\mathrm{~N}$ \\
\hline
\end{tabular}

*This patient received a Boston keratoprosthesis type I.

PCN: penicillin; NSAID: nonsteroidal anti-inflammatory drug.

implicated is sulfamethoxazole [2], a sulfonylarylamine component of a commonly used combination antibiotic also containing trimethoprim. Re-administration of trimethoprim-sulfamethoxazole to a patient who previously developed SJS/TEN due to the same drug can cause recurrent SJS/TEN [23]. Numerous sources now support an absence of cross-reactivity between acetazolamide, a non-sulfonylarylamine, in patients with allergy to sulfamethoxazole $[10,14,24,25]$.

Despite a common $\mathrm{SO}_{2} \mathrm{NH}_{2}$ group, there are two critical structural differences which distinguish sulfonamide antimicrobials such as sulfamethoxazole and sulfonamide nonantimicrobials such as acetazolamide; and these differences distinguish the drugs chemically and immunologically. Allergic reactions to sulfamethoxazole represent IgE-mediated immediate hypersensitivity reactions to the $\mathrm{N} 1$ heterocyclic ring, a structural component absent in acetazolamide [12,15]. Metabolite formation and subsequent specific cytotoxic $\mathrm{T}$ cell responses is stereospecific to the N4 amino nitrogen of sulfamethoxazole, also not found in acetazolamide [12,15].

Caution is indicated when prescribing any drug to a patient with prior SJS/TEN. However, in such patients acetazolamide should not be feared more than other drugs, even when the inciting agent for the original SJS/TEN was sulfamethoxazole. An interesting comparison may be made to celecoxib, another sulfonamide nonantibiotic [26]. Between January and June of 1999, 7 million prescriptions were written but only two possible cases of SJS/TEN were reported. If the risk of celecoxib causing SJS/TEN was similar to sulfamethoxazole, 7 million prescriptions would result in 30 to 70 cases of SJS/TEN [2,26]. This additional evidence supports a lack of cross reactivity induced by the two classes of sulfonamides.

In such a rare disorder as SJS/TEN, randomized clinical trials cannot be performed. Our retrospective case series includes too few patients to determine that acetazolamide is safe in patients with prior SJS/TEN. However, it is reassuring that we were able to safely administer acetazolamide to patients with a history of SJS/TEN, even the two patients reporting a "sulfa" allergy. We have not administered acetazolamide to any patient with sulfamethoxazole induced SJS/TEN. However, our case series is generally supportive of the use of acetazolamide in patients with a history of SJS/TEN, a population thought to have a higher incidence of drug-induced hypersensitivity.

\section{Conclusions}

In conclusion, individuals with a history of SJS/TEN should be approached conservatively when it comes to administration of any medication. Safety measures such as skin testing, low test-dose administration of medication orally while under direct supervision, and HLA testing [21] may increase confidence in specific cases. In the setting of keratoprosthesis, oral acetazolamide may be the only medication short of glaucoma surgery which can lower intraocular pressure. We currently use oral acetazolamide in patients with SJS/TEN after implantation of the Boston 
keratoprosthesis type II as a temporizing measure for elevated intraocular pressure in the early postoperative period, and chronically in select patients with glaucoma shunt failure.

\section{Availability of supporting data}

There is no supporting data beyond Table 1 .

\section{Abbreviation}

SJS/TEN: Stevens-Johnson syndrome/toxic epidermal necrolysis.

\section{Completing interests}

The authors declare they have no competing interests or conflicts of interest associated with this manuscript.

\section{Acknowledgements}

Funded in part by an unrestricted grant to the Department of Ophthalmology, Harvard Medical School, from Research to Prevent Blindness, New York, NY. The sponsor played no role in any aspect of the study.

\section{Authors' contributions}

James Chodosh accepts full responsibility for the work. RK and JC performed the literature review and patient chart review. RK, CHD, and JC drafted, read, and approved the manuscript.

Received: 10 November 2011 Accepted: 30 April 2012

Published: 30 April 2012

\section{References}

1. Borchers AT, Lee JL, Naguwa SM, Cheema GS, Gershwin ME: Stevens-Johnson syndrome and toxic epidermal necrolysis. Autoimmun Rev 2008, 7(8):598-605.

2. Roujeau JC, Kelly JP, Naldi L, Rzany B, Stern RS, Anderson T, Auquier A, Bastuji-Garin S, Correia O, Locati F, et al: Medication use and the risk of Stevens-Johnson syndrome or toxic epidermal necrolysis. N Engl J Med 1995, 333(24):1600-1607.

3. Harr T, French LE: Toxic epidermal necrolysis and Stevens-Johnson syndrome. Orphanet J Rare Dis 2010, 5(1):39.

4. Power WJ, Ghoraishi M, Merayo-Lloves J, Neves RA, Foster CS: Analysis of the acute ophthalmic manifestations of the erythema multiforme/ Stevens-Johnson syndrome/toxic epidermal necrolysis disease spectrum. Ophthalmology 1995, 102(11):1669-1676.

5. Chang YS, Huang FC, Tseng SH, Hsu CK, Ho CL, Sheu HM: Erythema multiforme, Stevens-Johnson syndrome, and toxic epidermal necrolysis: acute ocular manifestations, causes, and management. Cornea 2007, 26 (2):123-129.

6. Sayegh RR, Ang LP, Foster CS, Dohlman CH: The Boston keratoprosthesis in Stevens-Johnson syndrome. Am J Ophthalmol 2008, 145(3):438-444.

7. Rivier D, Paula JS, Kim E, Dohlman CH, Grosskreutz CL: Glaucoma and keratoprosthesis surgery: role of adjunctive cyclophotocoagulation. $J$ Glaucoma 2009, 18(4):321-324.

8. Kumar RS, Tan DT, Por YM, Oen FT, Hoh ST, Parthasarathy A, Aung T: Glaucoma management in patients with osteo-odonto-keratoprosthesis (OOKP): the Singapore OOKP Study. J Glaucoma 2009, 18(5):354-360.

9. Yu JF, Liang L, Huang YF: Stevens-Johnson syndrome and acetazolamide. J Glaucoma 2010, 19(8):568. author reply 568.

10. Strom BL, Schinnar R, Apter AJ, Margolis DJ, Lautenbach E, Hennessy S, Bilker WB, Pettitt D: Absence of cross-reactivity between sulfonamide antibiotics and sulfonamide nonantibiotics. N Engl J Med 2003, 349 (17):1628-1635.

11. Wolkenstein P, Carriere V, Charue D, Bastuji-Garin S, Revuz J, Roujeau JC, Beaune P, Bagot M: A slow acetylator genotype is a risk factor for sulphonamide-induced toxic epidermal necrolysis and Stevens-Johnson syndrome. Pharmacogenetics 1995, 5(4):255-258.

12. Brackett CC: Sulfonamide allergy and cross-reactivity. Curr Allergy Asthma Rep 2007, 7(1):41-48.

13. Chung WH, Hung SI, Yang JY, Su SC, Huang SP, Wei CY, Chin SW, Chiou CC, Chu SC, Ho HC, et al: Granulysin is a key mediator for disseminated keratinocyte death in Stevens-Johnson syndrome and toxic epidermal necrolysis. Nat Med 2008, 14(12):1343-1350.
14. Greenberger PA: 8. Drug allergy. J Allergy Clin Immunol 2006, 117(2):464-470.

15. Knowles SR, Uetrecht J, Shear NH: Idiosyncratic drug reactions: the reactive metabolite syndromes. Lancet 2000, 356(9241):1587-1591.

16. Naisbitt DJ, Hough SJ, Gill HJ, Pirmohamed M, Kitteringham NR, Park BK: Cellular disposition of sulphamethoxazole and its metabolites: implications for hypersensitivity. Br J Pharmacol 1999, 126(6):1393-1407.

17. Nassif A, Bensussan A, Boumsell L, Deniaud A, Moslehi H, Wolkenstein P, Bagot M, Roujeau JC: Toxic epidermal necrolysis: effector cells are drug-specific cytotoxic T cells. J Allergy Clin Immunol 2004, 114(5):1209-1215.

18. Shear NH, Spielberg SP, Grant DM, Tang BK, Kalow W: Differences in metabolism of sulfonamides predisposing to idiosyncratic toxicity. Ann Intern Med 1986, 105(2):179-184.

19. Ferrell PB Jr, MCLeod HL: Carbamazepine, HLA-B*1502 and risk of Stevens-Johnson syndrome and toxic epidermal necrolysis: US FDA recommendations. Pharmacogenomics 2008, 9(10):1543-1546.

20. Kim SH, Kim M, Lee KW, Kang HR, Park HW, Jee YK: HLA-B*5901 is strongly associated with methazolamide-induced Stevens-Johnson syndrome/ toxic epidermal necrolysis. Pharmacogenomics 2010, 11(6):879-884.

21. Sheffield LJ, Phillimore HE: Clinical use of pharmacogenomic tests in 2009. Clin Biochem Rev 2009, 30(2):55-65.

22. Murata J, Abe R, Shimizu H: Increased soluble Fas ligand levels in patients with Stevens-Johnson syndrome and toxic epidermal necrolysis preceding skin detachment. J Allergy Clin Immunol 2008, 122(5):992-1000.

23. Azinge NO, Garrick GA: Stevens-Johnson syndrome (erythema multiforme) following ingestion of trimethoprim-sulfamethoxazole on two separate occasions in the same person: a case report. J Allergy Clin Immunol 1978, 62(2):125-126

24. Johnson KK, Green DL, Rife JP, Limon L: Sulfonamide cross-reactivity: fact or fiction? Ann Pharmacother 2005, 39(2):290-301.

25. Lee AG, Anderson R, Kardon RH, Wall M: Presumed "sulfa allergy" in patients with intracranial hypertension treated with acetazolamide or furosemide: cross-reactivity, myth or reality? Am J Ophthalmol 2004, 138 (1):114-118.

26. Knowles S, Shapiro L, Shear NH: Should celecoxib be contraindicated in patients who are allergic to sulfonamides? Revisiting the meaning of 'sulfa' allergy. Drug Saf 2001, 24(4):239-247.

doi:10.1186/1756-0500-5-205

Cite this article as: Kumar et al:: Oral Acetazolamide after Boston

Keratoprosthesis in Stevens Johnson Syndrome. BMC Research Notes 2012 5:205.

\section{Submit your next manuscript to BioMed Central and take full advantage of:}

- Convenient online submission

- Thorough peer review

- No space constraints or color figure charges

- Immediate publication on acceptance

- Inclusion in PubMed, CAS, Scopus and Google Scholar

- Research which is freely available for redistribution 